\title{
Solanine Induces Mitochondria-Mediated Apoptosis in Human Pancreatic Cancer Cells
}

\author{
Hongwei Sun, ${ }^{1}$ Chongqing Lv, ${ }^{1}$ Longlong Yang, ${ }^{1}$ Yingxiu Wang, \\ Qingshun Zhang, ${ }^{1}$ Suhui Yu, ${ }^{1}$ Hongru Kong, ${ }^{1}$ Meng Wang, ${ }^{1}$ Jianming Xie, \\ Chunwu Zhang, ${ }^{2}$ and Mengtao Zhou ${ }^{1,2}$ \\ ${ }^{1}$ Department of Surgery, First Affiliated Hospital of Wenzhou Medical University, Wenzhou 325000, China \\ ${ }^{2}$ Wenzhou Key Laboratory of Surgery, Department of Surgery, First Affiliated Hospital of Wenzhou Medical University, \\ Wenzhou 325000, China
}

Correspondence should be addressed to Mengtao Zhou; zmt0417@hotmail.com

Received 16 December 2013; Revised 19 February 2014; Accepted 15 April 2014; Published 11 May 2014

Academic Editor: M. Piacentini

Copyright (C) 2014 Hongwei Sun et al. This is an open access article distributed under the Creative Commons Attribution License, which permits unrestricted use, distribution, and reproduction in any medium, provided the original work is properly cited.

\begin{abstract}
Steroid alkaloids have been suggested as potential anticancer compounds. However, the underlying mechanisms of how steroid alkaloids inhibit the tumor growth are largely unknown. Here, we reported that solanine, a substance of steroid alkaloids, has a positive effect on the inhibition of pancreatic cancer cell growth in vitro and in vivo. In pancreatic cancer cells and nu/nu nude mice model, we found that solanine inhibited cancer cells growth through caspase-3 dependent mitochondrial apoptosis. Mechanically, solanine promotes the opening of mitochondrial membrane permeability transition pore (MPTP) by downregulating the Bcl2/Bax ratio; thereafter, Cytochrome $\mathrm{c}$ and Smac are released from mitochondria into cytosol to process the caspase-3 zymogen into an activated form. Moreover, we found that the expression of tumor metastasis related proteins, MMP-2 and MMP-9, was also decreased in the cells treated with solanine. Therefore, our results suggested that solanine was an effective compound for the treatment of pancreatic cancer.
\end{abstract}

\section{Introduction}

Pancreatic cancer is a malignant neoplasm, which causes the death of more than 30 thousand people per year in the United States [1]. Pancreatic cancer has extremely poor prognosis and less effective response to conventional therapy compared with other kinds of cancers. The 5-year relative survival rate of pancreatic cancer patients is about $6 \%$, and the median survival time after diagnosis is up to 6 months [2-4]. Though the surgical resection of pancreatic cancer in the head is the most effective treatment, only $20 \%$ of the cases are surgically resectable [5]. Alternatively, a high proportion of pancreatic cancer patients have to be treated with radiation or chemotherapy rather than surgery. However, the survival rates in those nonsurgical pancreatic cancer patients were not changed. Thus, a novel effective therapeutic method or agent is needed for the treatment of those nonsurgical patients.

Solanine, one of the steroid alkaloids, belongs to the Solanaceae family. Solanine is mainly found in the tuber of potato (Solanum tuberosum L.) and the plant of nightshade (Solanum nigrum Linn.). The total alkaloids had a strong inhibitory effect on tumor growth in animals due to its cytotoxic effect on tumor cells $[6,7]$. Further experiments showed that the ethanol extract of total alkaloids from ripe fruits exhibited proapoptotic effect on breast cancer cells [8]. This anticancer effect was further confirmed in another kind of steroid alkaloids in the family of Solanaceae [9].

As of now, the study of other compounds of Solanaceae family such as solanine is limited. To uncover the potential contribution of solanine to the cancer therapy and the potential mechanisms that underlie the relationships between solanine and tumorigenesis, the effect of solanine on pancreatic cancer was studied in this study.

\section{Materials and Methods}

2.1. Cell Lines and Nude Mice. Human pancreatic cancer cell lines, SW1990 and Panc-1 (Shanghai Institutes for Biological 
TABLE 1: Primer pairs used in RT-PCR in vitro and in vivo.

\begin{tabular}{|c|c|c|}
\hline Genes & Primers $\left(5^{\prime}-3^{\prime}\right)$ & $\mathrm{BP}$ \\
\hline \multicolumn{3}{|c|}{ In vitro } \\
\hline \multirow{2}{*}{ Bax } & Forward ACAAAGATGGTCACGGTCTGCC & \multirow{2}{*}{242} \\
\hline & Reverse ACCAAGAAGCTGAGCGAGTGTC & \\
\hline \multirow{2}{*}{$\mathrm{Bcl}-2$} & Forward GCTCT TCAGG GACGG GGT & \multirow{2}{*}{166} \\
\hline & Reverse GACAG CCAGG AGAAA TCAAA CAG & \\
\hline \multirow{2}{*}{ P53 } & Forward TTCCG AGAGC TGAAT GAGGC & \multirow{2}{*}{435} \\
\hline & Reverse TTTTT ATGGC GGGAG GTAGA CT & \\
\hline \multirow{2}{*}{ Cytc } & Forward AGACA TGGAG ACCAA AATCA AGAAC & \multirow{2}{*}{132} \\
\hline & Reverse CTCCT TTAGC GGTCA TTGCC & \\
\hline \multirow{2}{*}{ Smac } & Forward AGCTG GAAAC CACTT GGATGA & \multirow{2}{*}{138} \\
\hline & Reverse GAATG TGATT CCTGG CGGTTA & \\
\hline \multirow{2}{*}{ MMP-2 } & Forward AATGC CATCC CCGAT AACC & \multirow{2}{*}{397} \\
\hline & Reverse GCTCA GCAGC CTAGC CAGTC & \\
\hline \multirow{2}{*}{ MMP-9 } & Forward GGGGG AAGAT GCTGC TGTT & \multirow{2}{*}{440} \\
\hline & Reverse AGCGG TCCTG GCAGA AATAG & \\
\hline \multirow{2}{*}{ GAPDH } & Forward GTCTT CACCA CCATG GAGAA & \multirow{2}{*}{267} \\
\hline & Reverse ATCCA CAGTC TTCTG GGTGG & \\
\hline \multirow{3}{*}{ Bax } & In vivo & \multirow{3}{*}{195} \\
\hline & Forward TGGCAGCTGACATGTTTTCTGAC & \\
\hline & Reverse CGTCCCAACCACCCTGGTCT & \\
\hline \multirow{2}{*}{$\mathrm{Bcl}-2$} & Forward GTCATGTGTGTGGAGAGCGT & \multirow{2}{*}{144} \\
\hline & Reverse GCCGTACAGTTCCACAAAGG & \\
\hline \multirow{2}{*}{ Caspase-3 } & Forward CAGACAGTGGAACTGACGAT & \multirow{2}{*}{152} \\
\hline & Reverse TTTCAGCATGGCGCAAAGTG & \\
\hline \multirow{2}{*}{ GAPDH } & Forward GGTGGAAGGTCGGTGTGAACG & \multirow{2}{*}{234} \\
\hline & Reverse CTCGCTCCTGGAAGATGGTG & \\
\hline
\end{tabular}

Sciences), were cultured in RPMI 1640 containing 10\% FBS. Cell density was adjusted to $2 \times 10^{4}$ cells per square centimeter before the addition of solanine (Sigma). Athymic nude nu/nu mice were obtained from the Shanghai Laboratory Animal Center at the Chinese Academy of Sciences, Shanghai, China. Animals were maintained at the Laboratory Animal Center of Wenzhou Medical University. The animal experiment protocol was approved by the Institutional Animal Committee of Wenzhou Medical University.

2.2. Cell Proliferation and Apoptosis Analysis. Cell proliferation was measured using the Cell Counting Assay Kit8 (Dojindo Molecular Technologies, Kumamoto, Japan) according to the manufacturer's protocol. Briefly, $0.6 \times 10^{4}$ cells were seeded in 96-well plate one day before the serum starvation procedure. After starving with the serum-free medium containing $0.1 \%$ BSA for $24 \mathrm{~h}$, cells were treated with different concentrations of solanine for $24 \mathrm{~h}, 48 \mathrm{~h}$, and $72 \mathrm{~h}$ as indicated. Then, cells were coincubated with Counting Assay Kit- 8 solution for another $2 \mathrm{~h}$. Cell viability was determined by measuring the absorbance at $450 \mathrm{~nm}$ using a plate reader (BioTek Instruments, USA). In the cells treated with solanine, the reduced percentages of cell viability compared with control cells without solanine were considered cell growth inhibition rates.
For the cell apoptosis analysis, cells with or without the treatment of solanine were stained with Annexin V/propidium iodide (PI) using Vybrant Apoptosis Assay Kit Number 2 (Molecular Probes). The apoptotic cells were analyzed by flow cytometry.

2.3. Quantitative Real-Time PCR. Total RNA were extracted from cultured cells or mice tissues with TRIzol Reagent (Ambion, NY, USA) following the manufacturer's instruction. The RNA quality was verified using spectrophotometric and agarose gel electrophoresis. Later on, the cDNA was synthesized with the ReverTra Ace qPCR RT kit (Toyobo, Tokyo, Japan) using $1 \mu \mathrm{g}$ RNA. Quantitative analyses of MMP-2, MMP-9, Bax, Bcl, p53, Smac, and Cytc mRNA expression were performed using SYBR Green Real-Time PCR Master Mix (Toyobo) on 7500 Real-Time PCR System (Applied Biosystems, Carlsbad, California, USA). The primers used here were listed in Table 1.

2.4. Immunoblotting. For the immunoblotting of P53, Bcl-2, Bax, and caspase-3, proteins were extracted from whole cell lysates using RIPA buffer (Cell Signaling) following manufacturer's instructions. For the immunoblotting of Cytochrome $c$ and Smac, cytoplasmic proteins were extracted using NEPER Nuclear Protein Extraction Kit (Thermo Fisher). The 


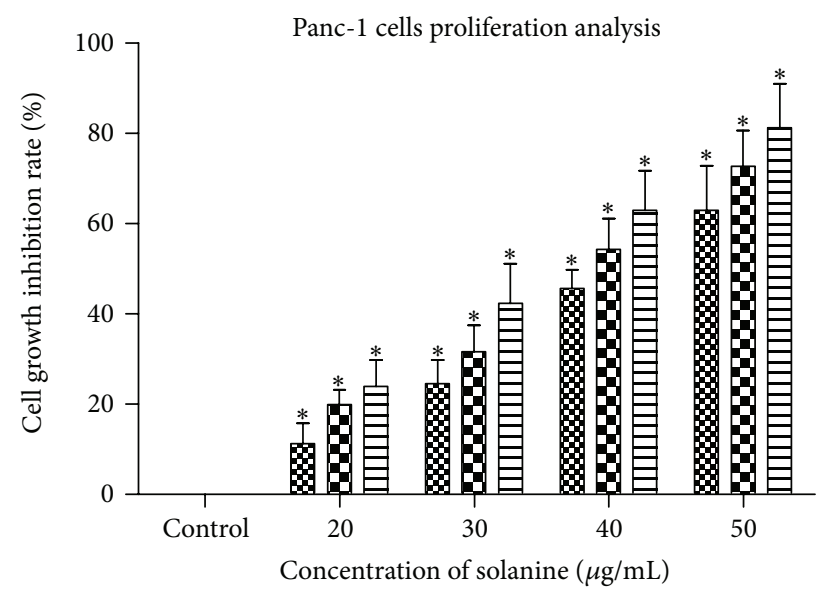

$8024 \mathrm{~h}$

Def $48 \mathrm{~h}$ $72 \mathrm{~h}$

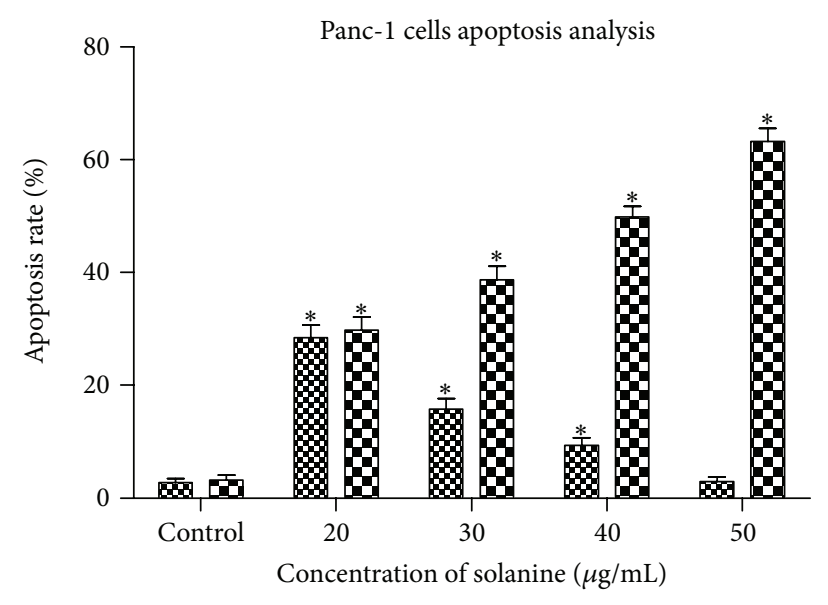

Barly apoptosis II. Late apoptosis (a)

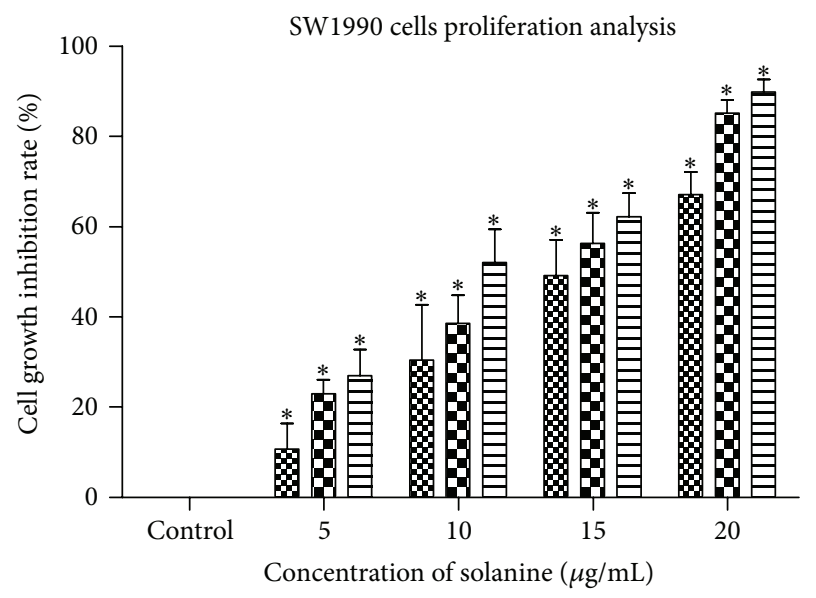

$8224 \mathrm{~h}$

Div $48 \mathrm{~h}$ $72 \mathrm{~h}$

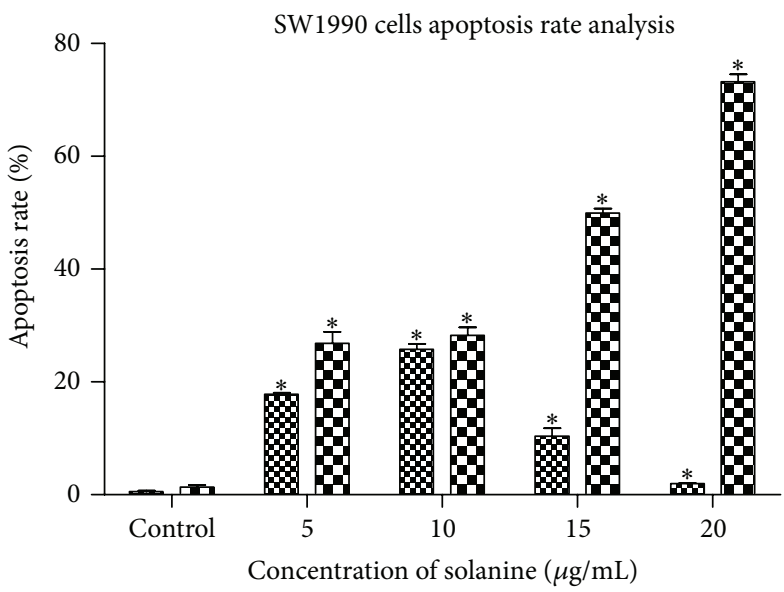

88 Early apoptosis III Late apoptosis

(c)

(d)

FIGURE 1: Solanine regulates pancreatic cancer cells viability. ((a) and (c)) After treatment with different solanine concentrations for $24 \mathrm{~h}, 48 \mathrm{~h}$, and $72 \mathrm{~h}$, cell growth inhibition rates were further calculated by determining the cell viability using CCK-8 in Panc-1 (a) and SW1990 (c) cells. ((b) and (d)) Apoptotic cells of Panc-1 (b) and SW1990 (d) cells were determined by treating the cells with different solanine concentration for $24 \mathrm{~h}$. The early and late apoptosis were measured using Annexin V and PI based flow cytometry, respectively. Error bars, \pm SD. ${ }^{*} P<0.05$.

proteins separated by SDS gel were transferred to $0.22 \mu \mathrm{m}$ PVDF membrane (Bio-Rad) at $15 \mathrm{~V}$ for $2 \mathrm{~h}$ by using semidry transfer set (CBS Scientific). After blocking the membranes with $5 \%$ nonfat dry milk in Tris-buffered saline with Tween (TBST) $(150 \mathrm{mM} \mathrm{NaCl}, 15 \mathrm{mM}$ Tris- $\mathrm{HCl}(\mathrm{pH} 7.5)$, and $0.1 \%$ Tween 20) for about $2 \mathrm{~h}$, proteins were probed with primary antibody against Bcl-2 (Bioworld), caspase-3 (Bioworld), P53 (Bioworld), Bax (Bioworld), Smac/Diablo (Cell Signaling), Cytochrome c (Cell Signaling), or $\beta$-actin antibody (Santa Cruz) and then incubated with a secondary antibody conjugated with horseradish peroxidase (Cell Signaling). Membranes were washed by TBST after each antibody probing. Signals were detected by using Super Signal West Pico chemiluminescent substrate (Thermo Scientific). Integrated optical density (IOD) quantification was performed using Gel-Pro Analyzer 4.0.

2.5. ELISA. MMP-2 and MMP-9 levels in the supernatant of cell culture were determined using the ELISA kit according to the manufacturer's instructions.

2.6. In Vivo Tumorigenesis Assay. Around $4 \times 10^{6}$ viable SW1990 cells were injected subcutaneously into 6-weekold nu/nu male nude mice. After 15 days of injection, the mice were divided into two groups (5/group) randomly and 


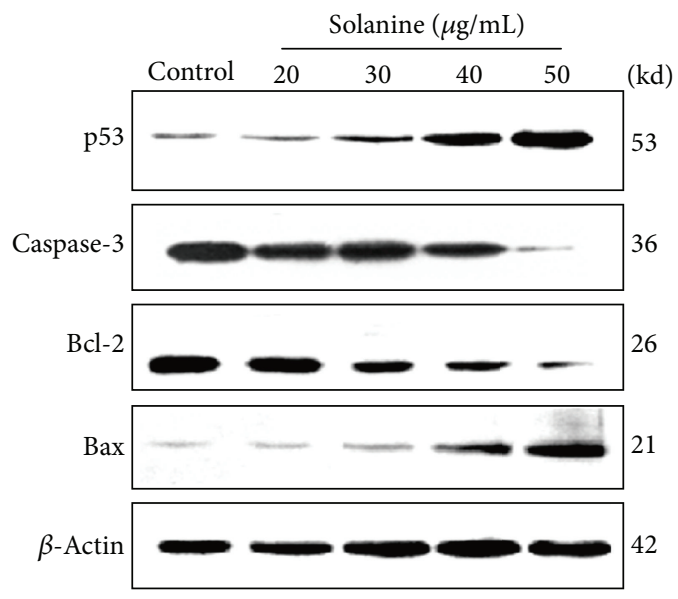

(a)
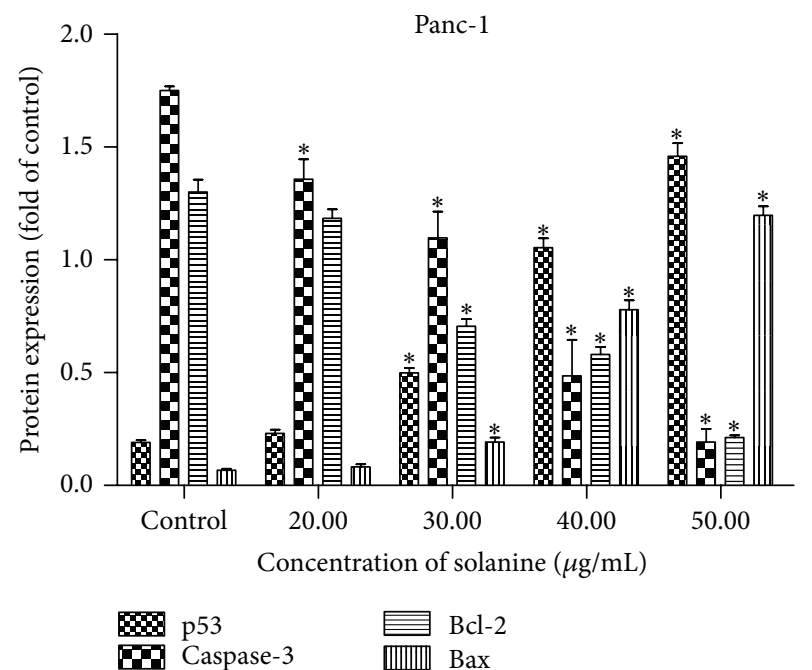

DO Caspase-3 (c)

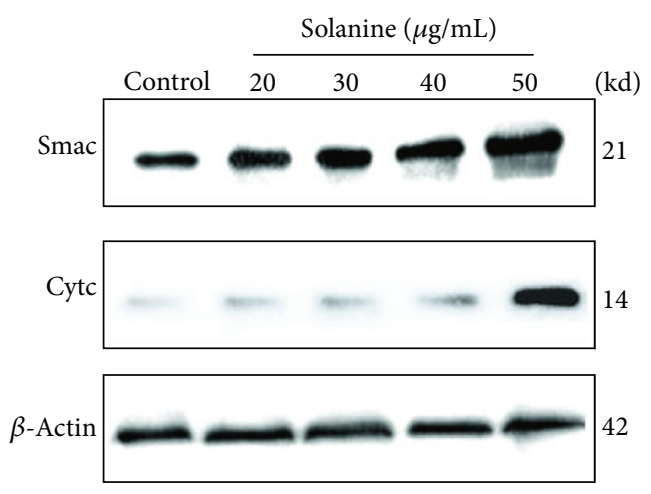

(b)

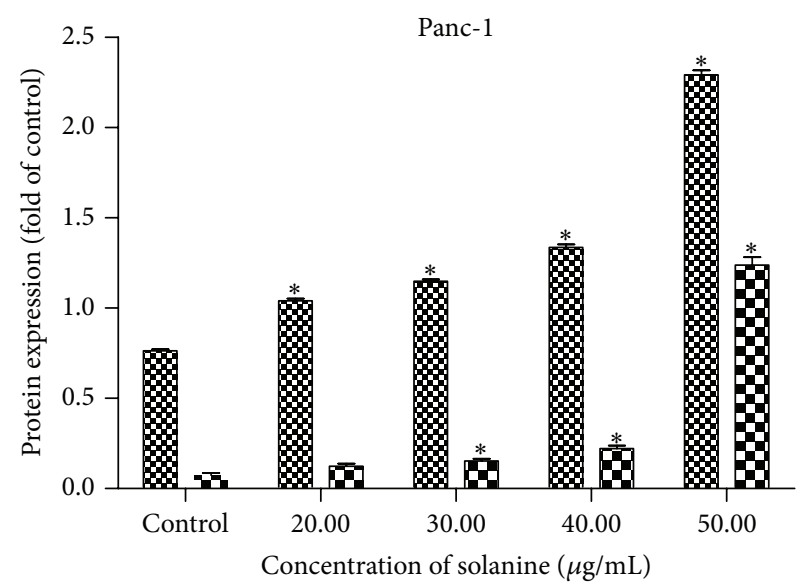

80 Smac DII Cytc

(d)

FIGURE 2: Solanine regulates mitochondrion mediated Panc-1 cell apoptosis. Immunoblot analysis of apoptosis related protein, Bcl-2, Bax, P53, caspase-3, Cytc, and Smac protein in Panc-1 cells. ((a) and (b)) Immunoblots analysis of whole cell lysates from Panc-1. Antibodies were used as indicated. ((c) and (d)) Immunoblots analysis of cytoplasmic protein extraction from Panc-1. Antibodies were used as indicated. Error bars, \pm SD. ${ }^{*} P<0.05$.

were fed with or without $5 \mathrm{mg} / \mathrm{kg}$ solanine as indicated for two weeks [10]. Tumors' sizes were measured daily in two dimensions with calipers. Furthermore, the mRNA levels of Bcl-2 and Bax were also determined by Real-Time PCR as described above.

2.7. Statistical Analysis. The data are presented as mean \pm SD from three independent experiments. Statistical significance was evaluated by one-way ANOVA among groups of cells and independent Student's $t$ test between groups in vivo with SPSS 13.0 software (IBM). $P<0.05$ was considered statistically significant.

\section{Results}

3.1. Effect of Solanine in Cell Proliferation and Apoptosis. We found that solanine changed cell morphology in both SW1990 and Panc- 1 cells. Cells without solanine had smooth cell membrane and elongated cell shape, while cells coincubated with solanine exhibited round and shrinking morphology in a dose-dependent manner.

Then, we asked whether solanine can inhibit cell proliferation and promote cell apoptosis. In CCK8 based cell proliferation experiment, we found that solanine had a significant inhibitory effect on the growth of SW1990 and Panc-1 cell lines in a time- and dose-dependent manner (Figures 1(a) and 1(c)). In cell apoptosis study, we used Annexin V/propidium iodide (PI) based flow cytometry to test the early and late apoptosis in cells with and without solanine. We found that the numbers of total apoptotic cells were increased when the SW1990 and Panc-1 cells were treated with solanine for $24 \mathrm{~h}$ (Figures 1(b) and 1(d)). Furthermore, an increased ratio of late apoptotic cells to early apoptotic cells was observed when the dosage of solanine in the culture of SW1990 and Panc-1 

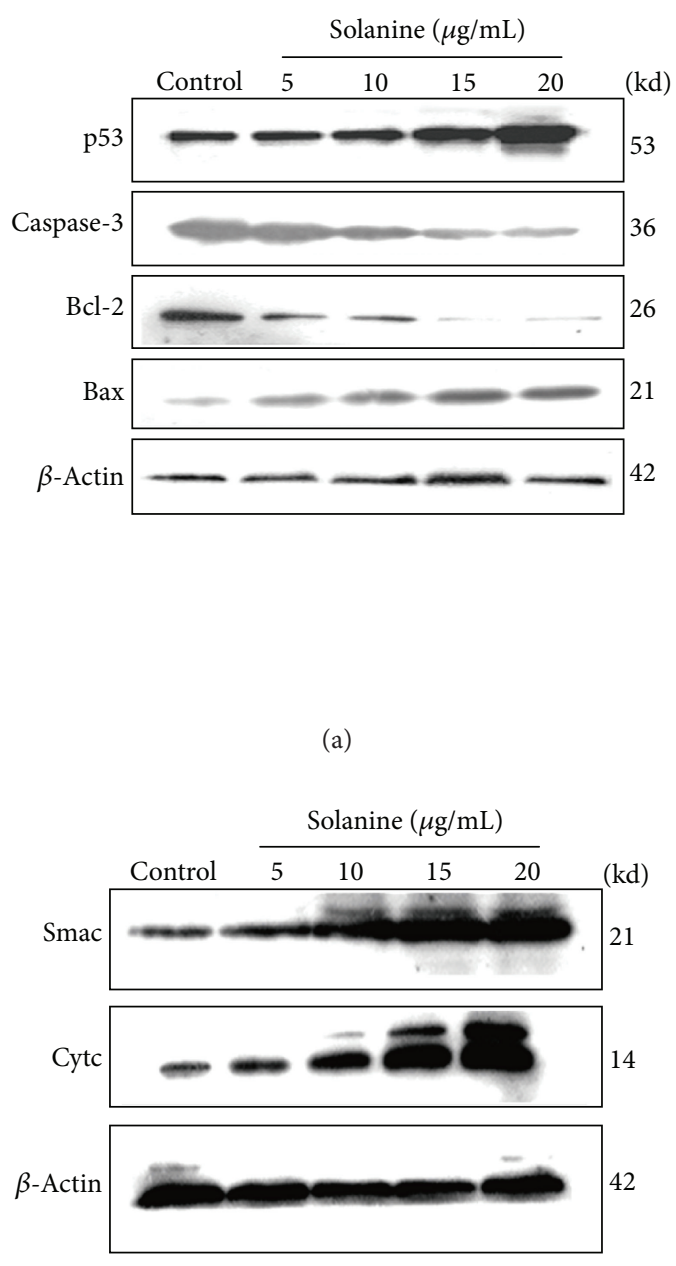

(c)

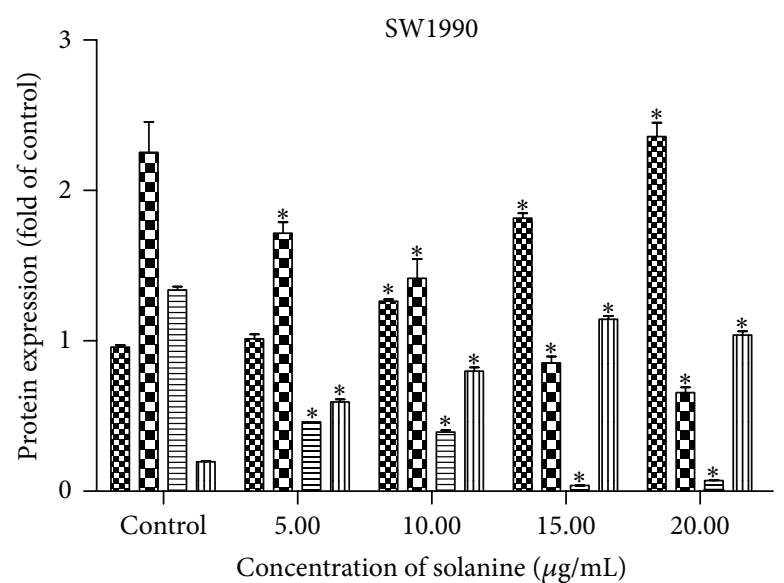

$\$ 0$ p53 产 Bcl-2

I. Caspase-3 血血 Bax

(b)

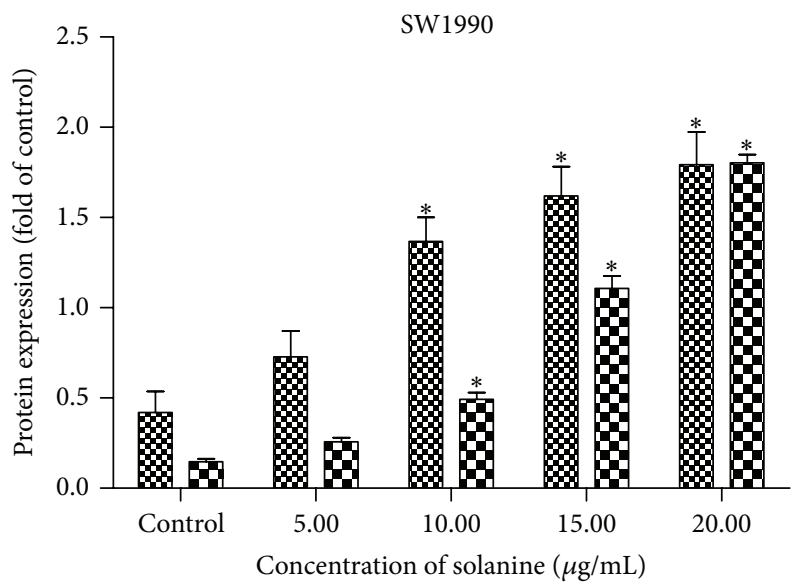

BS Smac Exitc

FIGURE 3: Solanine regulates mitochondrion mediated SW1990 cell apoptosis. Immunoblot analysis of apoptosis related protein, Bcl-2, Bax, P53, caspase-3, Cytc, and Smac, in SW1990 cells. ((a) and (b)) Immunoblots analysis of whole cell lysates from SW1990. Antibodies were used as indicated. ((c) and (d)) Immunoblots analysis of cytoplasmic protein extraction from SW1990. Antibodies were used as indicated. Error bars, \pm SD. ${ }^{*} P<0.05$.

cells increased (Figures $1(\mathrm{~b})$ and $1(\mathrm{~d})$ ). It suggested that the apoptotic effect was dose-dependent.

\subsection{Solanine Regulate Mitochondria-Mediated Cell Apoptosis} and Tumor Metastasis. To investigate the possible mechanism of solanine in the apoptosis of pancreatic cancer cells, we measured the abundance of several apoptosis related proteins in cells with and without solanine treatment (Figures 2 and 3). In Panc-1 (Figures 2(a) and 2(b)) and SW1990 (Figures 3(a) and 3(b)) cells, we found the cells treated with solanine containing higher P53 and Bax and lower Bcl2 levels, which means that the mitochondrial membrane permeability transition pore (MPTP) was opened in these cells due to the decreased $\mathrm{Bcl}-2 / \mathrm{Bax}$ ratio. As a consequence, the increased Cytochrome $\mathrm{c}$ and Smac levels were found in cytosol (Figures 2(c), 2(d), 3(c), and 3(d)). These results were further confirmed at mRNA level in Panc-1 (Figures 4(a) and 4(b)) and SW1990 cells (Figures 4(c) and 4(d)) with and without solanine. To confirm that the release of Cytochromes c and Smac from mitochondria into cytosol plays an initial role in mitochondrial apoptosis, we verified the expression of downstream proteins of Cytochrome c. As shown in Figures 2(a), 2(b), 3(a), and 3(b), we found that the caspase- 3 zymogen level was decreased in whole cells. Taken together, our results demonstrated that a caspase-3 dependent mitochondria apoptosis was activated in pancreatic cells treated with solanine.

To further test whether solanine can affect tumor metastasis, we determined the level of tumor metastasis related 

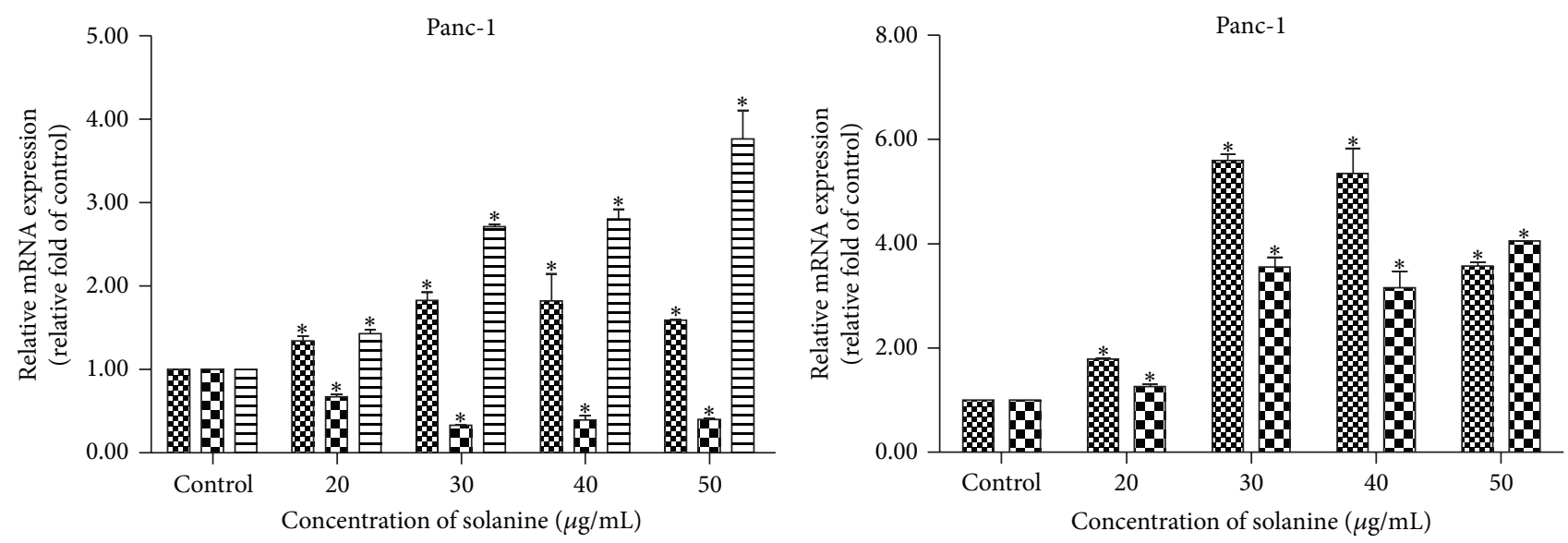

B Bax

B Smac

Fin $\mathrm{Bcl}$

Iin Cytc

(a)

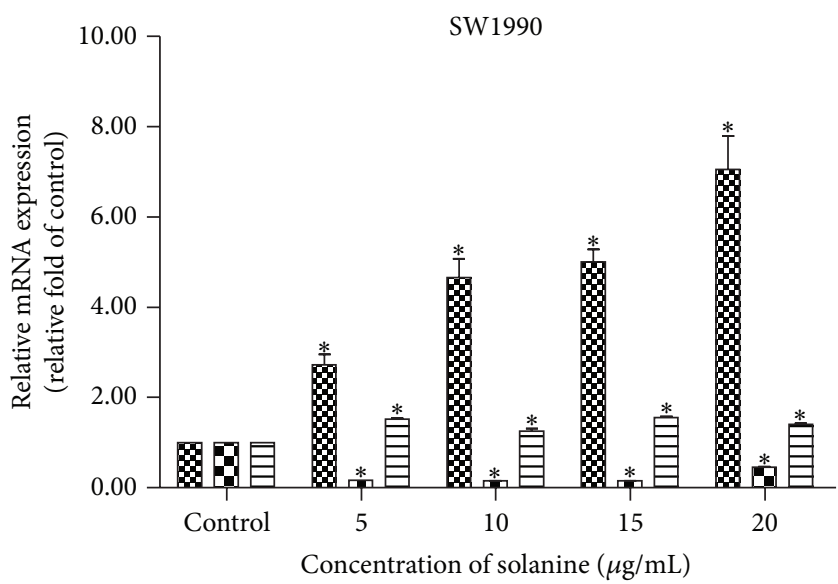

B8 Bax

Bcl

p 53

Concentration of solanine $(\mu \mathrm{g} / \mathrm{mL})$

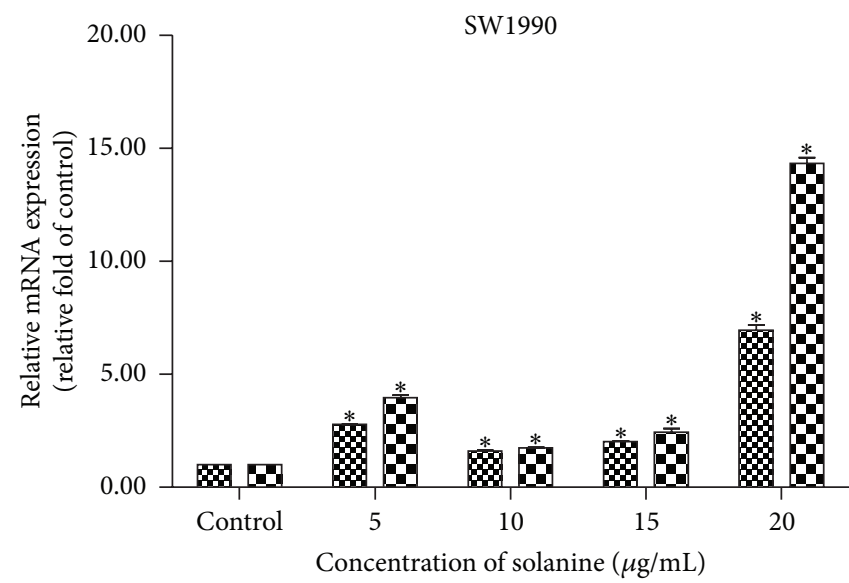

\$ Smac

Bin Cytc

(c)

(d)

FIGURE 4: Solanine regulates mitochondrion mediated pancreatic cancer cells apoptosis. Quantitative RT-PCR analysis of apoptosis related mRNA level, Bcl-2, Bax, P53, Cytc, and Smac, in Panc-1 ((a) and (b)) and SW1990 ((c) and (d)) cells.

TABLE 2: The immunohistochemistry analysis of Bax, caspase-3, and Bcl-2 in tumor xenografts.

\begin{tabular}{|c|c|c|c|c|c|c|}
\hline \multirow{2}{*}{ Groups } & \multirow{2}{*}{$n$} & \multicolumn{2}{|c|}{$\mathrm{Bax}$} & \multicolumn{2}{|c|}{ Bcl-2 } & \multirow{2}{*}{$P$ value } \\
\hline & & + & - & + & - & \\
\hline Control group & 50 & 19 & 11 & 39 & 31 & \\
\hline $5 \mathrm{mg} / \mathrm{kg}$ group & 50 & 29 & 20 & 30 & 21 & $<0.05$ \\
\hline
\end{tabular}

$P$ value is of the control group versus solanine groups.

marker proteins, MMP-2 and MMP-9, in Panc-1 and SW1990 cells. Quantitative RT-PCR showed that the mRNA levels of MMP-2 and MMP-9 were decreased in Panc-1 (Figure 5(a)) and SW1990 cells (Figure 5(b)) treated with solanine. At protein level, we found that the expression levels of MMP-2 and MMP-9 were upregulated in a dose-dependent manner in the supernatant of Panc-1 (Figures 5(c) and 5(d)) and SW1990 (Figures 5(e) and 5(f)) cells treated with solanine. These results suggested that solanine can regulate the tumor metastasis in pancreatic cancer.

3.3. Solanine Inhibits Tumorigenicity. To investigate the influence of solanine in the tumor formation of pancreatic cancer, we injected $4 \times 10^{6} \mathrm{SW} 1990$ cells into nu/nu nude mice. The mice treated with $5 \mathrm{mg} / \mathrm{kg}$ solanine resulted in a dramatic reduction of tumor size (Figure 6(a)). In the mice fed with solanine, an increased Bax and a decreased Bcl-2 level 

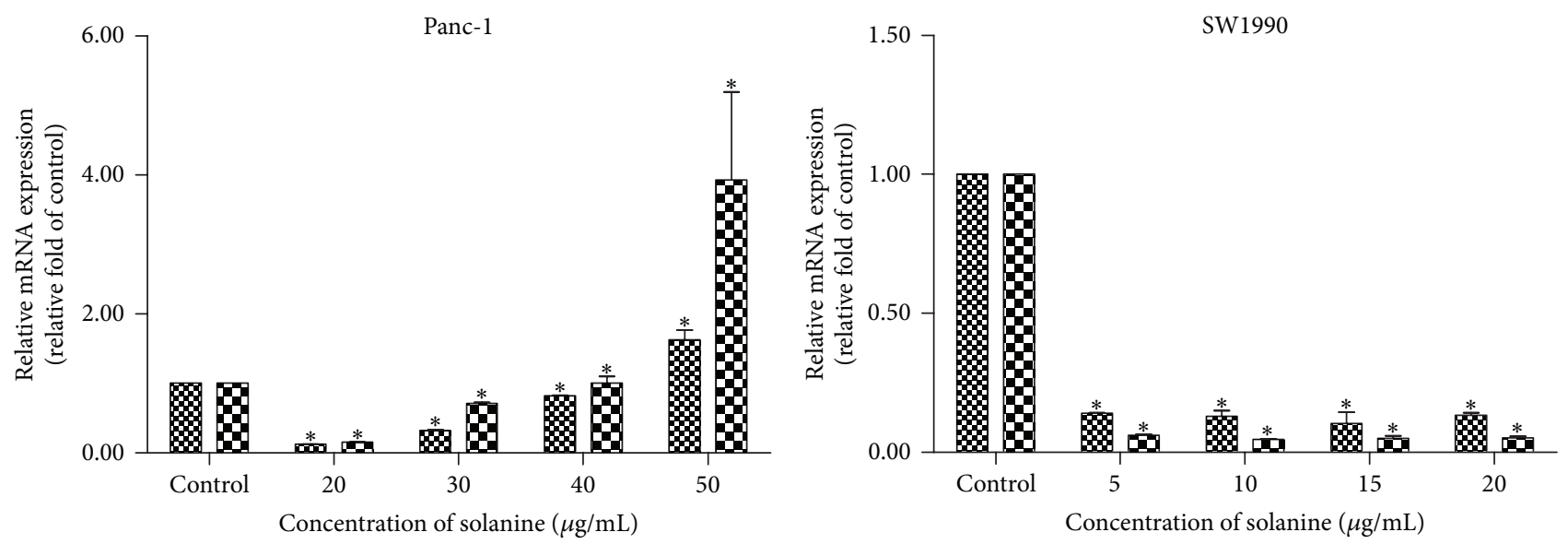

8 MMР-2

DI. MМР-9

(a)
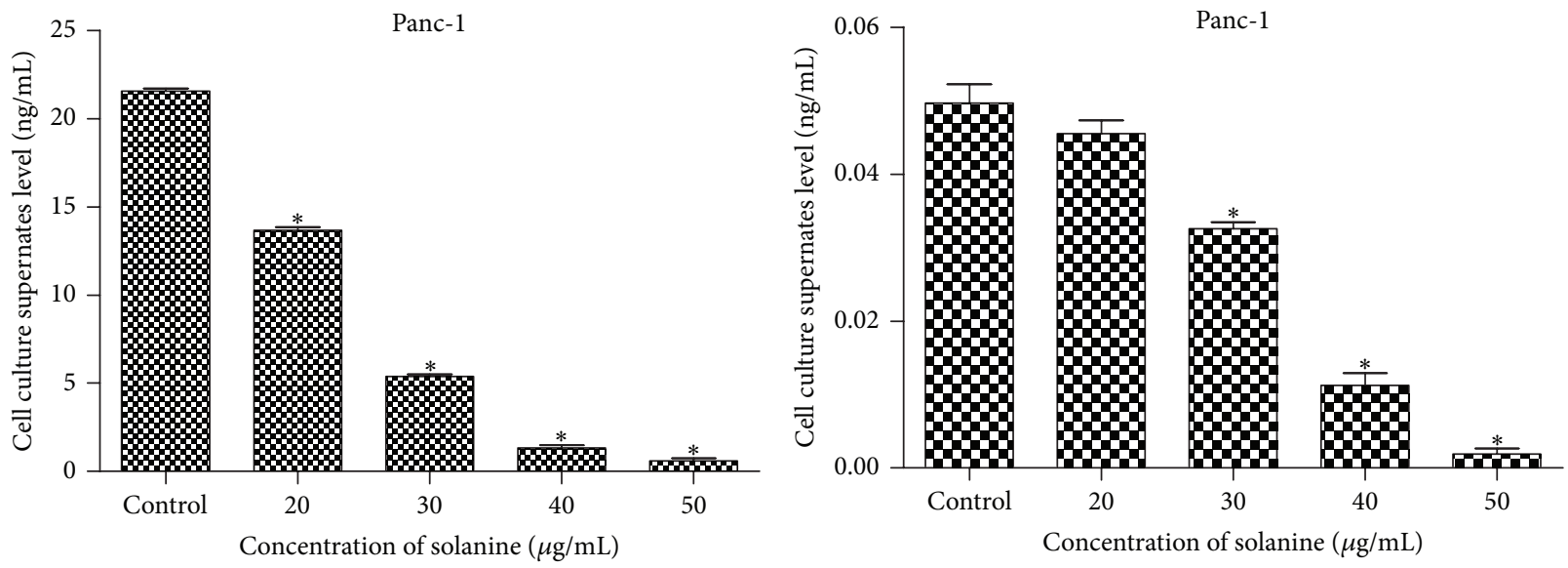

80 MMP-2

10 MМР-9

(c)

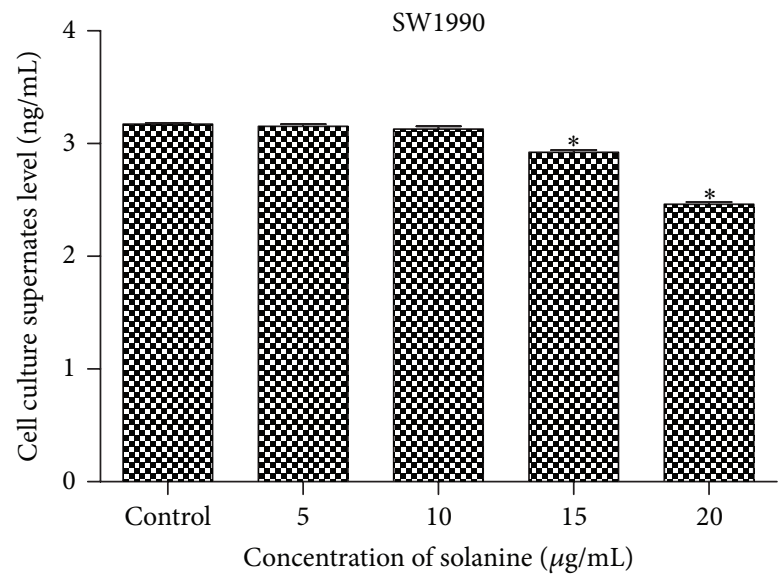

(\$) MMP-2

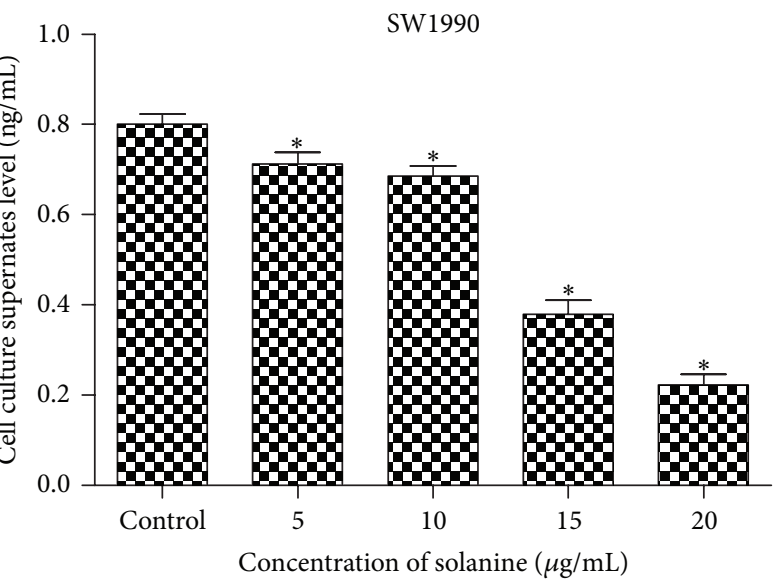

107 ММР-9

(e)

(f)

Figure 5: Solanine inhibits tumor metastasis ((a) and (b)). After $24 \mathrm{~h}$ of treatment of different solanine concentration, the mRNA level of MMP-2 and MMP-9 in Panc-1 (a) and SW1990 (b) was determined by quantitative RT-PCR. ((c)-(f)) After $24 \mathrm{~h}$ of treatment of different solanine concentrations, the protein level of MMP-2 and MMP-9 in Panc-1 ((c) and (d)) and SW1990 ((e) and (f)) cells was measured by ELISA. Error bars, \pm SD. ${ }^{*} P<0.05$. 


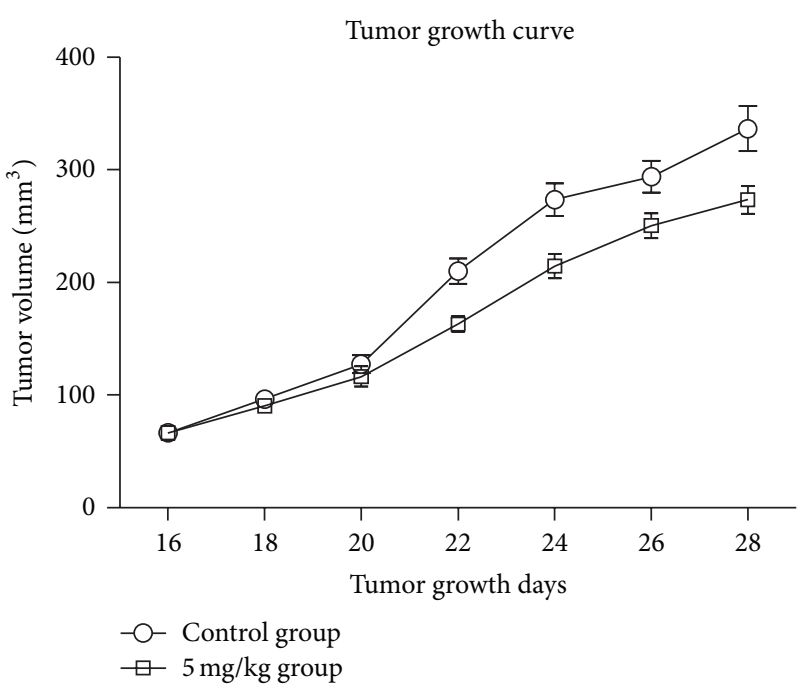

(a)

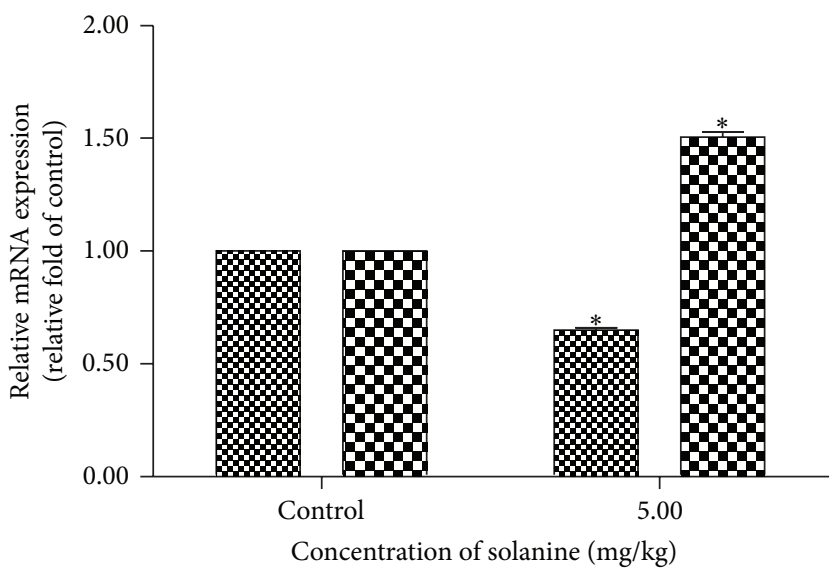

$88 \mathrm{Bcl}-2$ ad Bax

FIGURE 6: Solanine suppressed tumor growth in a xenograft model of pancreatic cancer. (a) $4 \times 10^{6}$ SW1990 cells were injected into nude mice. Three independent experiments with five mice in each group were used in this experiment. After 15 days of injection, mice were fed with solanine at $5 \mathrm{mg} / \mathrm{kg}$. After each 2 days, tumor size was measured in the mice fed with or without solanine. (b) Quantitative RT-PCR results of Bcl-2 and Bax in the xenograft tumor derived cells. Error bars, $\pm \mathrm{SD} .{ }^{*} P<0.05$.

were found at both mRNA (Figure 6(b)) and protein levels (Table 2). Thus, our results indicated that solanine has an inhibitory effect on tumor growth in vivo, which is probably through mitochondria-mediated cell apoptosis.

\section{Discussion}

Previous studies showed that steroid alkaloids, such as solasonine, solamargine, and solanine, exhibited an anticancer effect due to their roles in the apoptosis of cancer cells [11-16]. To date, no such reports were found in pancreatic cancer. In this study, we first observed the cytotoxic effect of solanine in two human pancreatic cancer cell lines, Panc-1 and SW1990, by using cell proliferation test and apoptosis assay. Further investigation showed that solanine bears an anticancer effect via the regulation of mitochondria-mediated cell apoptosis.

As we all know, apoptosis occurs in two-principal pathways: the mitochondria-mediated pathway and the death receptor-mediated pathway $[17,18]$. The death receptor-mediated pathway is triggered by the binding of death-inducing ligands to cell surface receptors. And the mitochondria-mediated pathway is triggered by a variety of apoptotic stimuli in mitochondria, which increases the permeability of mitochondrial membrane and causes the release of Cytochrome $\mathrm{c}$ and Smac into the cytoplasm [19-22]. It has been known that the ratio of Bcl-2 to Bax determines the response to a death signal via modulating the mitochondrial membrane permeability transition (MTP) pore formation [23]. Decreased $\mathrm{Bcl}-2$ loses the ability to inhibit the MTP pore formed by Bax complex, while increased Bax promotes the pore formation directly [23]. In our study, we found a decreased Bcl-2 and an increased Bax in solanine treated pancreatic cells. It indicated that solanine might activate mitochondria-mediated apoptosis by increasing the permeability of the mitochondrial membrane. Moreover, we found solanine treated cells containing higher Cytochrome $\mathrm{c}$ and Smac level in cytoplasmic and less of full length inactivated caspase- 3 in whole cells [19]. Thus, we speculated that solanine can induce caspase- 3 dependent mitochondrial apoptosis, in which solanine increases the permeability of mitochondrial membrane and releases Cytochrome c and Smac from mitochondria into cytosol to activate the caspase-9. Caspase-9 can then go on to activate caspase- 3 by truncating the full length inactivated caspase- 3 into activated forms, which are responsible for the cell apoptosis. Furthermore, our suggestion was further validated by checking the level of P53, which was found to be upregulated in caspase-3 dependent mitochondrial apoptosis [24]. Besides, our results indicated that solanine can also inhibit the process of metastasis by downregulating the expression of cancer cells migration related proteases, MMP-2 and MMP-9 $[25,26]$.

In conclusion, we demonstrated the mechanism of solanine as a cancer inhibitor in pancreatic cancer cell lines, by which we hope to give a new sight into the importance of solanine in the treatment of pancreatic cancer. However, further investigations are still needed to carefully clarify the side effects.

\section{Conflict of Interests}

The authors declare that there is no conflict of interests regarding the publication of this paper.

\section{Authors' Contribution}

Hongwei Sun and Chongqing Lv contributed equally to this work. 


\section{Acknowledgments}

The study was supported by a China National Natural Science Foundation Grant (nos. 81070372, 81370563), the Zhejiang Provincial Program for the Cultivation of High-Level Innovative Health Talents, and the Provincial Administration of Traditional Chinese Medicine of Zhejiang Province, China (no. 2011ZA072); the project was supported by the Ministry of Health of China, the Major Medicine Science and Technology Project in Zhejiang Province (no. WKJ2012-2-033), and the Public Welfare Technology Application Research Project was supported by the Science Technology Department of Zhejiang Province (no. 2012C23108), the Excellent Youth Foundation of Zhejiang Provincial Natural Science (no. LR14H030001), and the Project of Science and Technology of Wencheng County and the District Research and Development Program of Longwan District of Wenzhou, Zhejiang, China (no. 2010YS5).

\section{References}

[1] E. T. Lam, P. M. Bracci, E. A. Holly et al., "Mitochondrial DNA sequence variation and risk of pancreatic cancer," Cancer Research, vol. 72, no. 3, pp. 686-695, 2012.

[2] T. J. Howard, "Pancreatic adenocarcinoma," Current Problems in Cancer, vol. 20, no. 5, pp. 281-328, 1996.

[3] A. Jemal, R. Siegel, J. Xu, and E. Ward, "Cancer statistics, 2010," CA: Cancer Journal for Clinicians, vol. 60, no. 5, pp. 277-300, 2010.

[4] B. Norsa’adah, A. Nur-Zafira, and A. Knight, "Pancreatic cancer in Universiti Sains Malaysia Hospital: a retrospective review of years 2001-2008," Asian Pacific Journal of Cancer Prevention, vol. 13, no. 6, pp. 2857-2860, 2012.

[5] J. Werner and M. W. Büchler, "Management of pancreatic cancer: recent advances," Deutsche Medizinische Wochenschrift, vol. 136, no. 36, pp. 1807-1810, 2011.

[6] M. Friedman, K. R. Lee, H. J. Kim, I. S. Lee, and N. Kozukue, "Anticarcinogenic effects of glycoalkaloids from potatoes against human cervical, liver, lymphoma, and stomach cancer cells," Journal of Agricultural and Food Chemistry, vol. 53, no. 15, pp. 6162-6169, 2005.

[7] C. I. Kuo, C. H. Chao, and M. K. Lu, "Effects of auxins on the production of steroidal alkaloids in rapidly proliferating tissue and cell cultures of Solanum lyratum," Phytochemical Analysis, vol. 23, no. 4, pp. 400-404, 2012.

[8] Y. O. Son, J. Kim, J. C. Lim, Y. Chung, G. H. Chung, and J. C. Lee, "Ripe fruits of Solanum nigrum L. inhibits cell growth and induces apoptosis in MCF-7 cells," Food and Chemical Toxicology, vol. 41, no. 10, pp. 1421-1428, 2003.

[9] L. Reddivari, J. Vanamala, S. H. Safe, and J. C. Miller Jr., "The bioactive compounds $\alpha$-chaconine and gallic acid in potato extracts decrease survival and induce apoptosis in LNCaP and PC3 prostate cancer cells," Nutrition and Cancer, vol. 62, no. 5, pp. 601-610, 2010.

[10] B. C. Patil, R. P. Sharma, D. K. Salunkhe, and K. Salunkhe, "Evaluation of solanine toxicity," Food and Cosmetics Toxicology, vol. 10, no. 3, pp. 395-398, 1972.

[11] S. A. Yang, S. H. Paek, N. Kozukue, K. R. Lee, and J. A. Kim, " $\alpha$-Chaconine, a potato glycoalkaloid, induces apoptosis of HT29 human colon cancer cells through caspase-3 activation and inhibition of ERK 1/2 phosphorylation," Food and Chemical Toxicology, vol. 44, no. 6, pp. 839-846, 2006.

[12] M. K. Lu, Y. W. Shih, T. T. C. Chien, L. H. Fang, H. C. Huang, and P. S. Chen, " $\alpha$-Solanine inhibits human melanoma cell migration and invasion by reducing matrix metalloproteinase2/9 activities," Biological and Pharmaceutical Bulletin, vol. 33, no. 10, pp. 1685-1691, 2010.

[13] S. H. Choi, S. H. Lee, H. J. Kim et al., "Changes in free amino acid, phenolic, chlorophyll, carotenoid, and glycoalkaloid contents in tomatoes during 11 stages of growth and inhibition of cervical and lung human cancer cells by green tomato extracts," Journal of Agricultural and Food Chemistry, vol. 58, no. 13, pp. 7547-7556, 2010.

[14] S. Y. Gao, Q. J. Wang, and Y. B. Ji, "Effect of solanine on the membrane potential of mitochondria in HepG2 cells and $\left[\mathrm{Ca}^{2+}\right]_{\mathrm{i}}$ in the cells," World Journal of Gastroenterology, vol. 12, no. 21, pp. 3359-3367, 2006.

[15] Y. B. Ji, S. Y. Gao, C. F. Ji, and X. Zou, "Induction of apoptosis in HepG2 cells by solanine and Bcl-2 protein," Journal of Ethnopharmacology, vol. 115, no. 2, pp. 194-202, 2008.

[16] J. Zhang and G. W. Shi, "Inhibitory effect of solanine on prostate cancer cell line PC-3 in vitro," National Journal of Andrology, vol. 17, no. 3, pp. 284-287, 2011.

[17] C. Muñoz-Pinedo, "Signaling pathways that regulate life and cell death: evolution of apoptosis in the context of self-defense," Advances in Experimental Medicine and Biology, vol. 738, pp. 124-143, 2012.

[18] D. R. Schultz and W. J. Harrington Jr., "Apoptosis: programmed cell death at a molecular level," Seminars in Arthritis and Rheumatism, vol. 32, no. 6, pp. 345-369, 2003.

[19] S. Shimizu, M. Narita, and Y. Tsujimoto, "Bcl-2 family proteins regulate the release of apoptogenic cytochrome $\mathrm{c}$ by the mitochondrial channel VDAC," Nature, vol. 399, no. 6735, pp. 483487, 1999.

[20] D. Spierings, G. McStay, M. Saleh et al., "Connected to death: the (unexpurgated) mitochondrial pathway of apoptosis," Science, vol. 310, no. 5745, pp. 66-67, 2005.

[21] B. Antonsson, "Mitochondria and the Bcl-2 proteins in apoptosis signaling pathways," Molecular and Cellular Biochemistry, vol. 256-257, no. 1-2, pp. 141-155, 2004.

[22] D. R. Green and G. Kroemer, "The pathophysiology of mitochondrial cell death," Science, vol. 305, no. 5684, pp. 626-629, 2004.

[23] G. Filomeni, S. Cardaci, A. M. Da Costa Ferreira, G. Rotilio, and M. R. Ciriolo, "Metabolic oxidative stress elicited by the copper(II) complex [Cu(isaepy)2] triggers apoptosis in $\mathrm{SH}$ SY5Y cells through the induction of the AMP-activated protein kinase/p38MAPK/p53 signalling axis: evidence for a combined use with 3-bromopyruvate in neuroblastoma treatment," Biochemical Journal, vol. 437, no. 3, pp. 443-453, 2011.

[24] M. T. Hemann and S. W. Lowe, "The p53-Bcl-2 connection," Cell Death and Differentiation, vol. 13, no. 8, pp. 1256-1259, 2006.

[25] K. C. Wu, S. T. Yang, T. C. Hsia et al., "Suppression of cell invasion and migration by propofol are involved in downregulating matrix metalloproteinase- 2 and p38 MAPK signaling in A549 human lung adenocarcinoma epithelial cells," Anticancer Research, vol. 32, no. 11, pp. 4833-4842, 2012.

[26] Y. H. Kim, H. J. Kwon, and D. S. Kim, "Matrix metalloproteinase 9 (MMP-9)-dependent processing of betaig-h3 protein regulates cell migration, invasion, and adhesion," The Journal of Biological Chemistry, vol. 287, no. 46, pp. 38957-38969, 2012. 

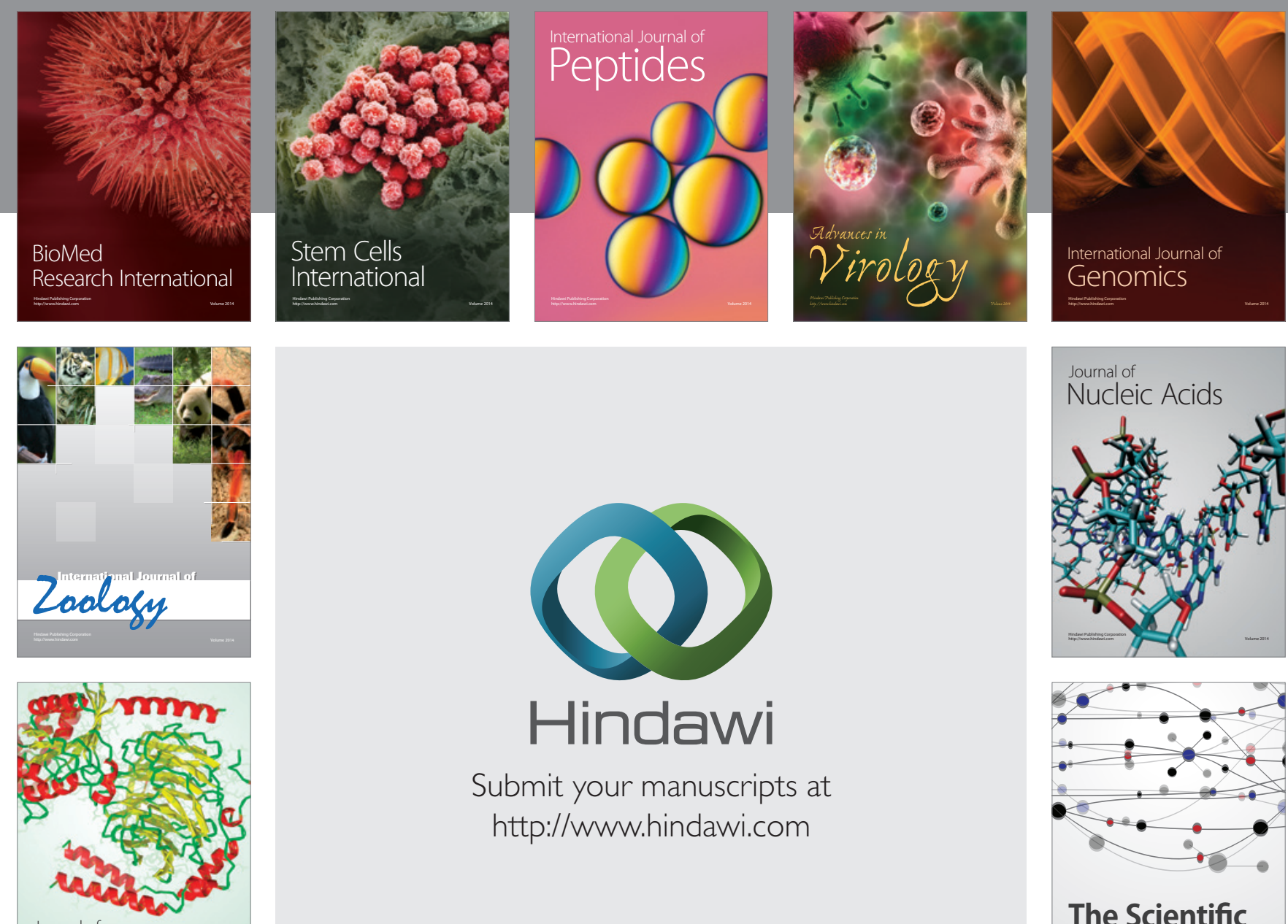

Submit your manuscripts at

http://www.hindawi.com

Journal of
Signal Transduction
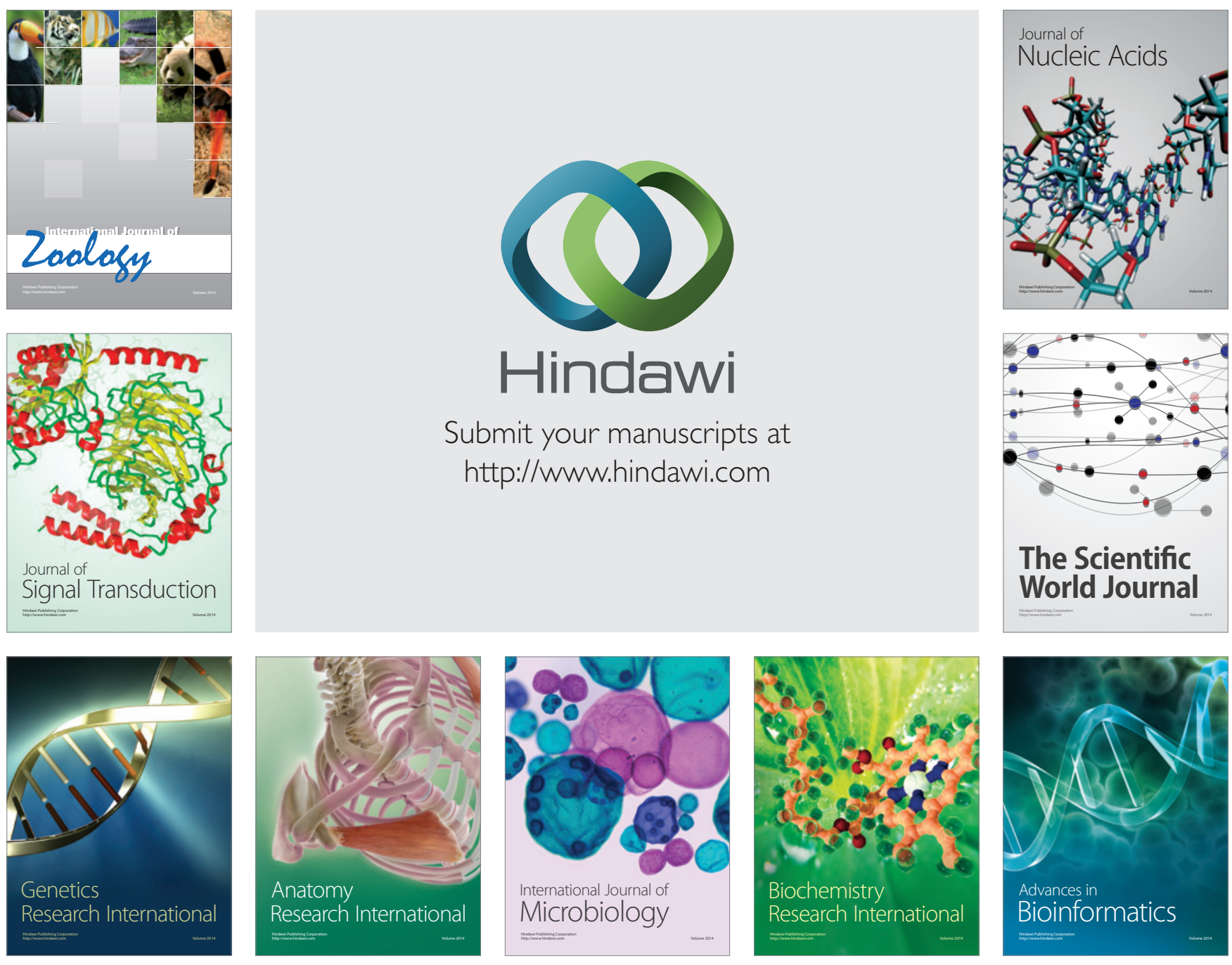

The Scientific World Journal
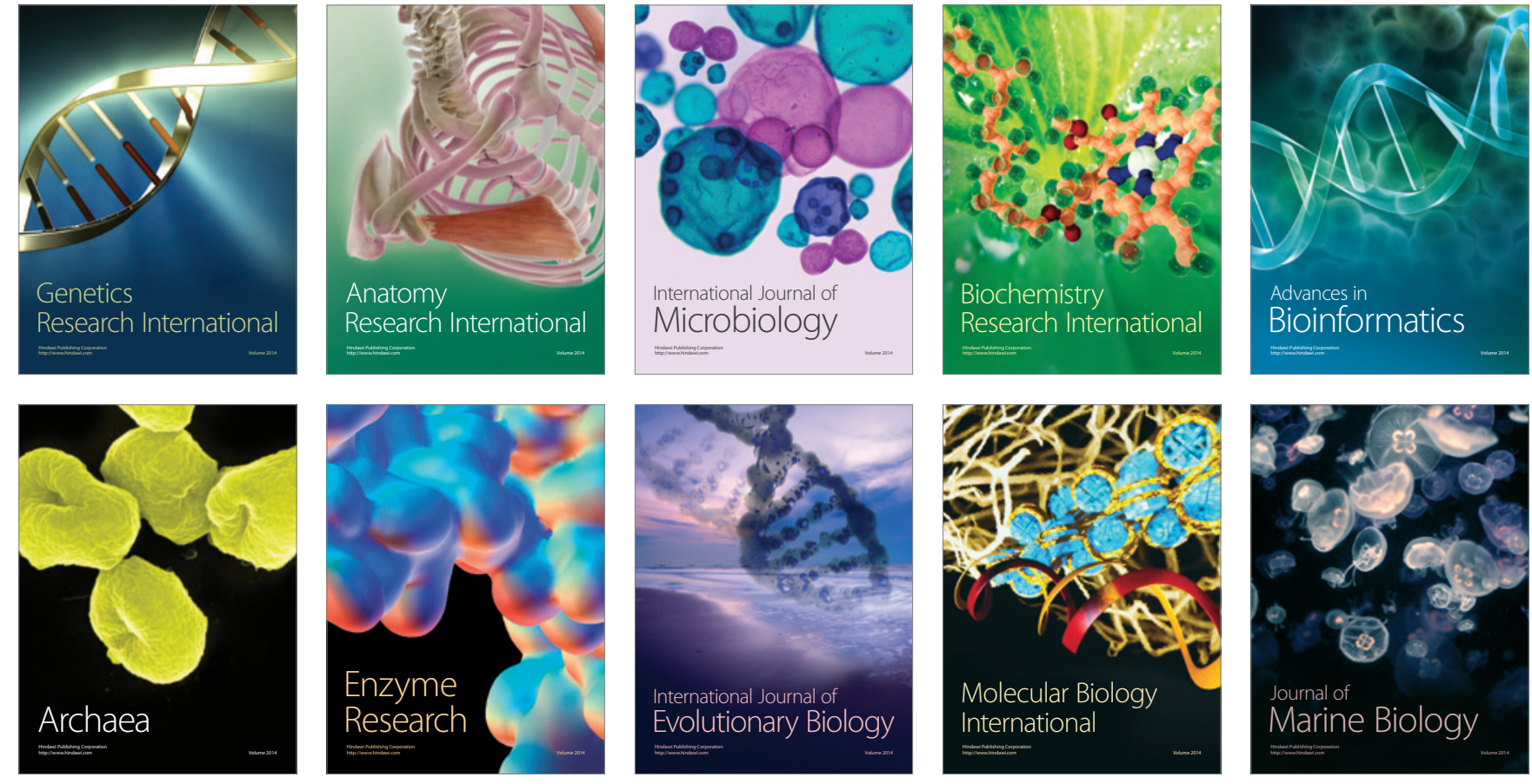